\title{
Limb Salvage Using Human Placental Allografts: Adding to the Reconstructive Ladder Paradigm
}

\author{
Stephanie Y. Ohara' ${ }^{1}$, Samantha A. Delapena ${ }^{1}$, William H. Tettelbach ${ }^{2,3,4}$, Lora Whooley ${ }^{3}$, \\ Sean F. 0’Keefe', Marc R. Matthews ${ }^{*}$ \\ ${ }^{1}$ Valleywise Health Medical Center, Creighton University, Phoenix, AZ, USA \\ ${ }^{2}$ Western Peak Specialty Hospital, Bountiful, UT, USA \\ ${ }^{3}$ MIMEDX Group, Inc., Marietta, GA, USA \\ ${ }^{4}$ Department of Anesthesiology, School of Medicine, Duke University, Durham, NC, USA \\ ${ }^{5} 3 \mathrm{M}$, St. Paul, MN, USA \\ ${ }^{6}$ Arizona Burn Center, Department of Surgery, Valleywise Health Medical Center, Phoenix, AZ, USA \\ Email: stephanieohara@creighton.edu,samanthadelapena@creighton.edu, btettelbach@mimedx.com,LWhooley@mimedx.com, \\ sokeefe2@mmm.com, *marc_matthews@dmgaz.org
}

How to cite this paper: Ohara, S.Y., Delapena, S.A., Tettelbach, W.H., Whooley, L., O'Keefe, S.F. and Matthews, M.R. (2022) Limb Salvage Using Human Placental Allografts: Adding to the Reconstructive Ladder Paradigm. Surgical Science, 13, 1-8. https://doi.org/10.4236/ss.2022.131001

Received: November 23, 2021

Accepted: January 2, 2022

Published: January 5, 2022

Copyright $\odot 2022$ by author(s) and Scientific Research Publishing Inc. This work is licensed under the Creative Commons Attribution International License (CC BY 4.0).

http://creativecommons.org/licenses/by/4.0/

\begin{abstract}
Human placental allografts are the latest treatment modalities for diabetic ulcers, chronic wounds, limbs, and tendons for healing cascade and promoting granulation tissue coverage. Purion ${ }^{\circledR}$ processed dehydrated human amnion/chorion membrane allografts (dHACM), decellularized human collagen matrix ( $\mathrm{dHCM})$, dehydrated umbilical cord (dHUC) and micronized dehydrated human amnion/chorion membrane allografts (mdHACM) have been the newest modality used to salvage injured human extremities with tendon and bone exposure. A 53-year-old male was assaulted and sustained second and third degree burns to both legs. The left extremity had a $9.5 \%$ total body surface area (\%TBSA) burned. The right extremity had a 5.5\% TBSA and three exposed tendons (Achilles/flexor digitorum longus/tibialis anterior), muscles, talar and tibial bones. Bilateral extremity pedal pulses were present, and all toes had less than two second capillary refill. Sensation, motor, and strength were normal. During the 48-day-hospital stay, the patient had eight operations: tangential excisional debridements of necrotic tissue with weekly wound dressing applications of $\mathrm{AHACM}$ and $\mathrm{AHCM}$, on both legs. In addition, dHUC was applied over the exposed tendons on weeks $2-5$. The exposed tendons were injected with mdHACM on weeks 4 and 5. Negative pressure wound therapy was applied at $125 \mathrm{mmHg}$ for fourteen days over the wound surfaces covered with a nonadherent dressing, 3\% bismuth tribromophenate petrolatum dressing with a glycerol-hydroxyethyl cellulose lubricant. At discharge for rehabilitation, 90\% of the split-thickness-skin-graft (STSG) was viable over the right ankle joint, tendons and bone. Use of human pla-
\end{abstract}


cental allografts prevented the need for myocutaneous flap coverage or amputation of the right foot.

\section{Keywords}

Limb Salvage, Placental Membranes, Amnion, Chorion, Umbilical Cord, Allograft, Burns, Trauma

\section{Introduction}

Davis (1909) and Sabella with Stern (1913) were pioneers in placental tissue applications for wound healing [1] [2] [3] [4]. Technology revolutionized the development of biological wound dressings for clinical use. Human placental allografts are the latest treatment modalities for chronic wounds, diabetic ulcers, limbs, and tendons [5]. Exposed bone or tendon in burn or trauma extremity injuries may require surgical flaps or amputations for healing. Purion ${ }^{\circledR}$ processed dehydrated human amnion/chorion membrane allografts (Dhacm, AMNIOBURN $^{\circledR}$ ), decellularized human collagen matrix ( $\left.\mathrm{AHCM}\right)$, dehydrated umbilical cord (dHUC, EPICORD ${ }^{\circledR}$ ), and micronized dehydrated human amnion/chorion membrane allografts (mdHACM) from MIMEDX Group, Inc. (Marietta, GA) have been used as an adjunct to salvage injured human extremities with tendon and bone exposure [6]-[11]. They contain non-viable cells, and over 250 identified regulatory proteins (growth factors, chemokines, cytokines, and metalloproteinases tissue inhibitors [TIMPS]) [6] [7] [8] [9]. In vivo, many of these regulatory proteins are known components in the tissue healing cascade. In vitro, these factors have been shown to stimulate tissue growth, regeneration, stem cell migration in animal models, fibroblast proliferation, and decreased inflammation [6] [7] [8] [9]. In 2017, Glat and Davenport recommended that placental allografts become adjuvant therapy in the surgical Reconstructive Ladder Paradigm for limb salvage [12]. Wound closure and limb salvage were successful with the combined application of $\mathrm{AHCM}$, and $\mathrm{DHACM}$, except for occasional difficulties with injured tendon and bone [11]. This case report illustrates successful limb salvage and full tendon/bone coverage with granulation tissue through the addition of dHUC allograft and mdHACM injections into the tendons. Placental allograft applications are described for limb reconstruction without the use of free tissue or rotational flaps.

\section{Case Report}

Our patient was a Hispanic man with a past medical history of gout and obesity (BMI $32 \mathrm{~kg} / \mathrm{m}^{2}$ ). He lived at home with his family (Table 1). While bicycling outside his home, he was assaulted with a Molotov cocktail and sustained second and third degree burns to both lower extremities. The left leg had a $9.5 \%$ total burn surface area (\%TBSA) and the right leg had a 5.5\% TBSA (Figure 1). Muscles, tendons (tibialis anterior, flexor digitorum longus, Achilles), talar and tibial 
Table 1. Patient demographics and characteristics.

\begin{tabular}{cc}
\hline Age & 52 \\
Race & Hispanic \\
Employed & Yes \\
Insurance & Yes \\
Height & $167.6 \mathrm{~cm}$ \\
Weight & $91.9 \mathrm{~kg}$ \\
BMI & $32 \mathrm{~kg} / \mathrm{m}^{2}$ \\
Co-morbidities & Gout \\
\hline
\end{tabular}
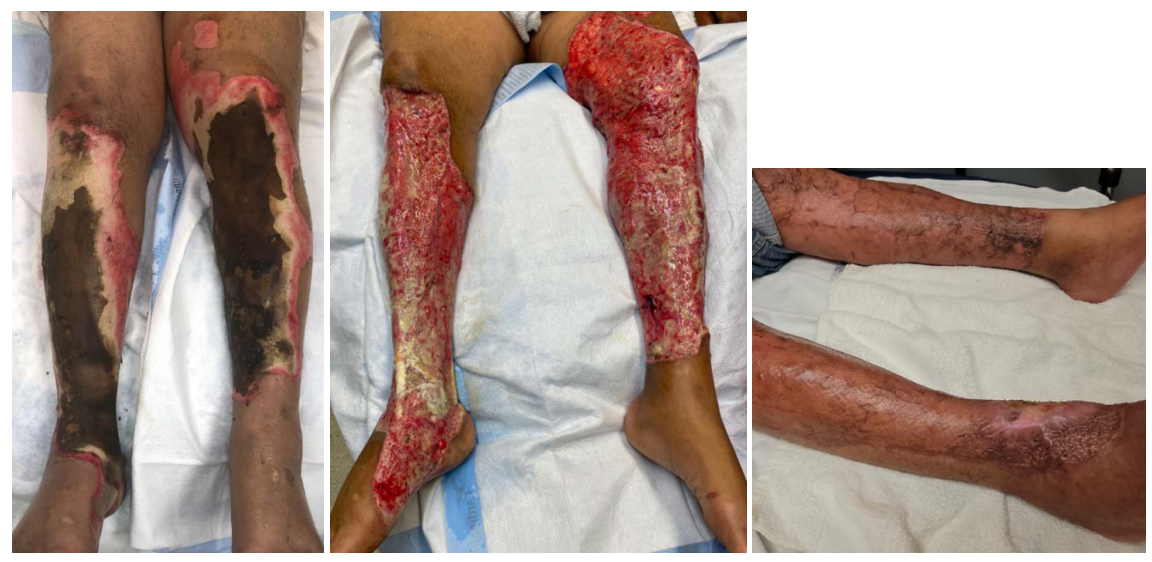

Figure 1. Second and third degree burn injuries; after initial debridement; and twenty-two weeks after initial injury.

bones were exposed on the right lower extremity. On initial exam, bilateral pedal pulses were present, and all toes had less than two second capillary refill. Sensation, motor, and strength were normal. During the 48-day-hospital stay, the patient had eight operations. There were weekly tangential excisional debridements of necrotic tissue with weekly application of one or more of the following placental allografts: dHACM, dHCM (Figure 2), dHUC (Figure 3), or mdHACM (Figure 4). The dHACM, dHCM and dHUC were used initially on both legs (week 2), then only on the right ankle (weeks 3 - 6). In addition, mdHACM was injected into the three exposed tendons of the right foot (weeks $4-5$ ). When a wound infection needed to be treated, a combination of intravenous antibiotics and a topical antispetic wash such as hypochlorous acid (Vashe Wound Solution, UMNA, Fort Worth, Texas) was used.

Table 2 shows the usage protocol for the different placental allografts. Table 3 provides the features and application of each placental allograft product. Before each application of the placental allografts, exposed talar or tibial bone was tangentially trephined (top layer of bone was removed using a large "pineapple" drill bit in a hand-held burring device, to expose bone arteriolar bleeding. Normal saline prevented frictional heat with the burring. The exposed tendons were trimmed superficially with scissors to remove any desiccated tissue. Then, dHACM, 


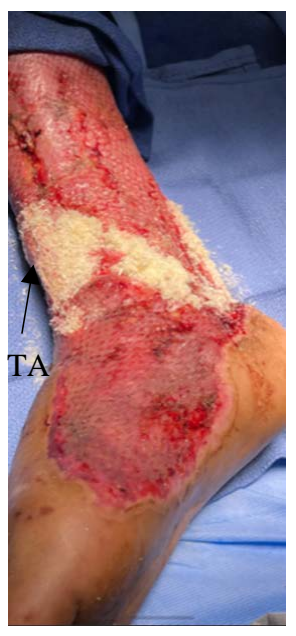

Figure 2. Application of dHCM over the exposed tendons.

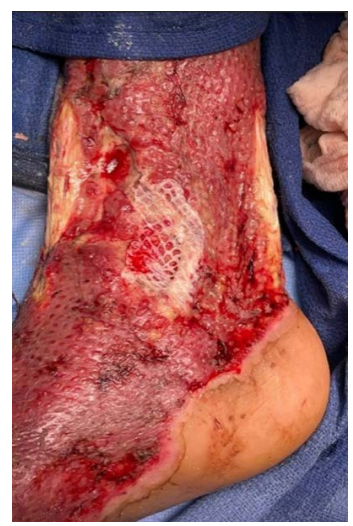

Figure 3. Application of dHUC over the flexor digitorum longus tendon.

Table 2. Weekly use of placental allografts on both legs and right foot.

\begin{tabular}{|c|c|c|c|c|c|c|c|}
\hline & Week & 2 & 3 & 4 & 5 & 6 & Total \\
\hline \multicolumn{2}{|c|}{ Tangential Excision/Debridement } & $\mathrm{x}$ & $\mathrm{x}$ & $\mathrm{x}$ & $\mathrm{x}$ & $\mathrm{x}$ & $3100 \mathrm{~cm}^{2}$ \\
\hline dHACM & ${ }^{*}$ AMNIOBURN ${ }^{\circledR}$ & $\begin{array}{l}\mathrm{xL} \\
\mathrm{x} \mathrm{R}\end{array}$ & & & $\mathrm{x} R$ & $\mathrm{x} R$ & $576 \mathrm{~cm}^{2}$ \\
\hline \multicolumn{2}{|l|}{$\mathrm{dHCM}$} & $\begin{array}{l}x \mathrm{~L} \\
\mathrm{x} \mathrm{R}\end{array}$ & $\mathrm{x} R$ & $\mathrm{x} R$ & & & $5500 \mathrm{mg}$ \\
\hline dHUC & ${ }^{\star} \mathrm{EPICORD}^{\circledR}$ & $\begin{array}{l}x L \\
x R\end{array}$ & $\mathrm{x} R$ & $x$ R & $\mathrm{x} \mathrm{R}$ & & $138 \mathrm{~cm}^{2}$ \\
\hline \multicolumn{2}{|c|}{ mdHACM } & & & $\mathrm{x} R$ & $\mathrm{x} R$ & & $320 \mathrm{mg}$ \\
\hline \multicolumn{2}{|c|}{ NPWT (125 mmHg) } & & & $\mathrm{x} R$ & $\mathrm{x} R$ & $\mathrm{xR}$ & 14 days \\
\hline \multicolumn{2}{|l|}{ STSG } & & $\mathrm{x} \mathrm{L}$ & $\mathrm{x} R$ & & $\begin{array}{l}x \mathrm{R} \\
\text { foot }\end{array}$ & $3450 \mathrm{~cm}^{2}$ \\
\hline \multicolumn{2}{|c|}{$\begin{array}{l}\text { Dressing: Petroleum gauze with } \\
\text { hydrophilic ointment }\end{array}$} & $\mathrm{x}$ & $\mathrm{x}$ & $\mathrm{x}$ & $\mathrm{x}$ & $\mathrm{x}$ & \\
\hline
\end{tabular}

*Placental Allografts: MIMEDX Group, Inc., Marietta, GA; L = left; R = right; NPWT = negative pressure wound therapy; STSG = split-thickness skin graft; tangential excision/debridement occurred twice on admission and on week 6. 


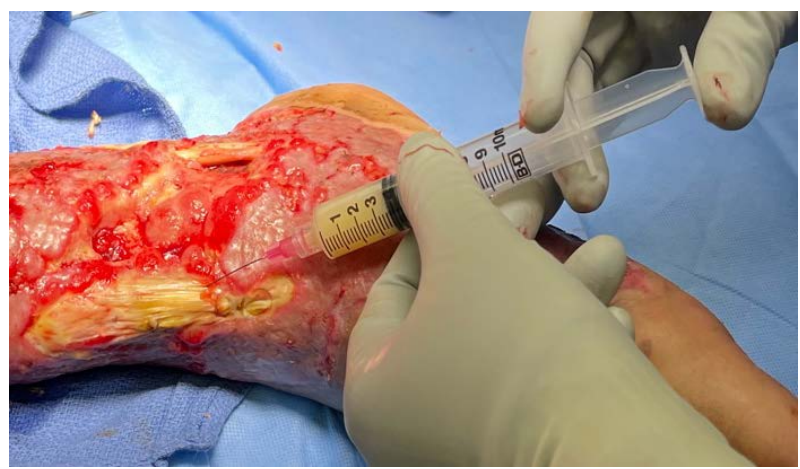

Figure 4. Injection of mdHACM the tibialis anterior tendon.

Table 3. Placental allografts features and application on both legs and right foot.

\begin{tabular}{|c|c|c|c|c|}
\hline & & Product Features & Product Application & $\begin{array}{l}\text { Product Cost } \\
61844 \text { \$USD }\end{array}$ \\
\hline dHCM & & $\begin{array}{l}\text { This thick powder should be removed } \\
\text { from glass vial with non-toothed forceps } \\
\text { and placed on the wound bed. If the vial } \\
\text { is cracked or broken, glass shards may } \\
\text { be introduced into the product. }\end{array}$ & $\begin{array}{l}\text { Placed directly over the freshly debrided } \\
\text { and hemostatic open wounds. It can be } \\
\text { slightly moistened and spread topically } \\
\text { as a paste over a wound bed or packed } \\
\text { into a freshly debrided soft tissue } \\
\text { fistulous tract. }\end{array}$ & 6435 \\
\hline dHACM & *AMNIOBURN ${ }^{\circledR}$ & $\begin{array}{l}\text { The product is like cellophane: } \\
\text { semi-transparent, either light tan or } \\
\text { orange, flexible and can be easily cut to } \\
\text { fit an atypical wound size. }\end{array}$ & $\begin{array}{l}\text { Cut to fit over the wound bed and apply } \\
\text { without getting the product wet. Can be } \\
\text { fenestrated by a scalpel \& applied directly } \\
\text { over the dHCM. The product is placed in } \\
\text { such a way that the written embossed } \\
\text { word on the product reads "Up". }\end{array}$ & 23,110 \\
\hline dHUC & ${ }^{\star}$ EPICORD $^{\circledR}$ & $\begin{array}{l}\text { It is brittle in its dehydrated form and } \\
\text { requires rehydration for approximately } \\
\text { ten seconds in a } 20 \mathrm{~mL} \text { normal saline } \\
\text { bath. Once rehydrated, it can be meshed } \\
\text { using a } 2: 1 \text { split thickness graft mesher. }\end{array}$ & $\begin{array}{l}\text { Applied directly over the trephined } \\
\text { bone. It can be cut to fit the desired area } \\
\text { after rehydration of the product. }\end{array}$ & 28,707 \\
\hline mdHACM & & $\begin{array}{l}\text { This solution can be injected into } \\
\text { exposed tendon, muscle, or subcutaneous } \\
\text { tissue. The volume used is left to the } \\
\text { discretion of the authorized medical } \\
\text { professional. Because the reconstituted } \\
\text { material is viscous, proper pre-injection } \\
\text { techniques reduce possible air } \\
\text { introduction. With time elapse, product } \\
\text { separates between rehydration and } \\
\text { administration: re-suspend by shaking } \\
\text { within } 12 \text { hours of reconstitution. }\end{array}$ & $\begin{array}{l}\text { Transfer the recommended volume of } \\
0.9 \% \text { sterile saline into the vial. With a } \\
\text { back-and-forth motion, transfer with the } \\
\text { plunger, and mix the particulate to } \\
\text { create a full suspension in the syringe. } \\
\text { Reconstituted } 160 \mathrm{mg} \text { in } 4 \mathrm{~mL} \text { sterile } \\
0.9 \% \text { saline using an } 18 \text {-gauge needle, is } \\
\text { injected into each tendon on weeks } 4 \& 5\end{array}$ & 3592 \\
\hline
\end{tabular}

${ }^{\star}$ Placental Allografts: MIMEDX Group, Inc., Marietta, GA; NPWT = negative pressure wound therapy.

dHUC or dHCM was applied directly over the freshly trephined bone and the tendons. In addition, mdHACM was also injected into the tendons. Wound sur- 
faces were covered with dressings made of petroleum gauze slathered with a hydrophilic ointment (Figure 5) followed by application of negative pressure wound therapy to bolster and promote healing (Figure 6). During the hospitalization, the patient underwent physical therapy to maintain strength and mobility in his feet and legs. At discharge for rehabilitation, $90 \%$ of the graft was viable over the right ankle joint, tendons and bone (Figure 1).

\section{Discussion}

The incorporation of four placental allografts (dHCM, dHACM, dHUC, and mdHACM) into this current limb salvage protocol preserved the extremity at risk for more invasive procedures-either a myocutaneous flap or amputation.

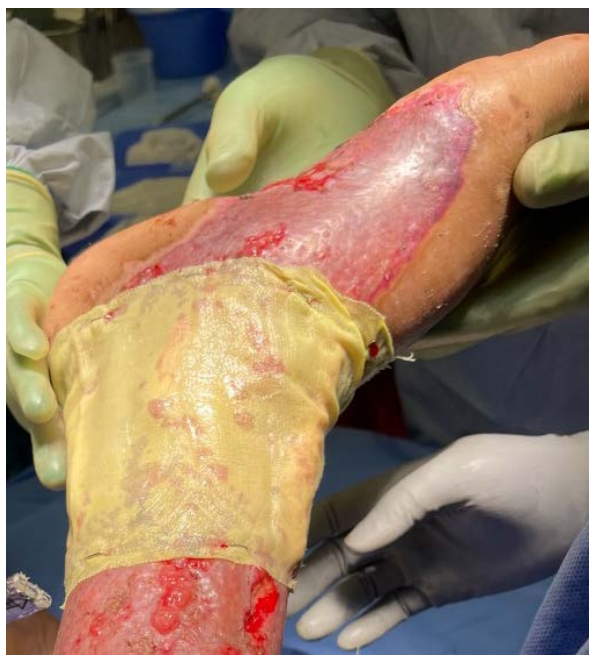

Figure 5. Application of nonadherent dressing, 3\% bismuth tribromophenate petrolatum dressing with a glycerol-hydroxyethyl cellulose lubricant.

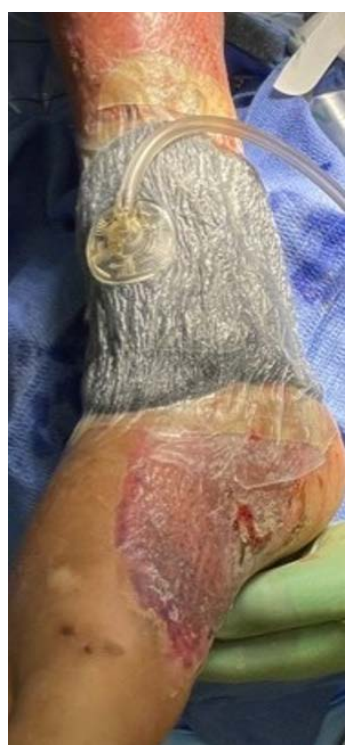

Figure 6. Application of negative pressure wound therapy with black granufoam over the nonadherent dressing. 
Specifically, the addition of dHUC over the bone and mdHACM injections into tendons created an environment for adequate granulation tissue growth to receive and sustain STSG coverage and wound closure. It has been postulated, along with our own past anecdotal clinical experience, that granulation tissue growth over inflamed or scarred tendons is difficult to generate. However, injections of mdHACM successfully supported tendon preservation and granulation tissue growth in this case [13].

A report about a viable, intact, and cryopreserved placental membrane (vCPM) (Grafix, Osiris Therapeutics, Columbia, MD) noted that seven (58\%) patients of twelve had successful wound closure with tendon exposure (size 17.5, range 4 $49 \mathrm{~cm}^{2}$ ) attached to or over a joint with an average eight (range $3-13 \mathrm{~cm}^{2}$ ) allograft applications [14]. The current patient had an acute burn injury with a much larger area of involvement $\left(3100 \mathrm{~cm}^{2}\right)$.

Ang and Chih-Kang have noted that placental membrane allografts aid in the “... normal healing cascade of hemostasis, inflammation, proliferation, and remodeling, ... because tendon regeneration occurs through three main phases: inflammation, proliferation, and remodeling ...” [15]. Fibroblast-induced scarring of the injured tendons can be reduced by placental membranes, because they contain hyaluronic acid, which dampens the upregulation of the biomarker, transforming growth factor- $\beta$ (TGF- $\beta$ ), which triggers fibroblasts to undergo a phenotypical change to become myofibroblasts and contribute to the scarring and fibrosis during healing [15].

\section{Conclusion}

In conclusion, the use of human placental allografts removed the necessity for myocutaneous flap coverage or an amputation of the right foot in this patient. mdHACM and dHUC were useful in covering the tendons with granulation tissue to form a bed for STSG coverage and adherence. A combination of placental allografts used to cover the wounds, deep tissue structures, and injectable products had a favorable impact in this patient's limb salvage outcome (Figure 1). By avoidance of the physical, financial, and psychological burdens associated with more invasive procedures typically considered in the standard reconstructive ladder, a vital quality of life (limb retention) was also achieved for the patient [11] [12].

\section{Conflicts of Interest}

There are no other conflicts of interest to declare.

\section{References}

[1] Davis, J.S. (1909) Skin Transplantation at the Johns Hopkins Hospital. Annals of Surgery, 50, 542-549. https://doi.org/10.1097/00000658-190909000-00002

[2] Davis, J.S. (1910) Skin Transplantation with a Review of 550 Cases at the Johns Hopkins Hospital. Johns Hopkins Medical Journal, 15, 307-396.

[3] Sabella, N. (1913) Use of the Fetal Membranes in Skin Grafting. Medication Recon- 
ciliation, 83, 478-480.

[4] Stern, M. (1913) The Grafting of Preserved Amniotic Membrane to Burned and Ulcerated Surfaces, Substituting Skin Grafts. JAMA, 60, 973-974.

https://doi.org/10.1001/jama.1913.04340130021008

[5] Glat, P.M. (2017) The Evolution of Burn Injury Management: Using Dehydrated Human Amnion/Chorion Membrane Allografts in Clinical Practice. Annals of Plastic Surgery, 78, S1. https://doi.org/10.1097/SAP.0000000000000982

[6] Koob, T., Renner, R., Zabek, N., Massee, M., Lim, J.J., Temenoff, J.S., et al. (2013) Biological Properties of Dehydrated Human Amnion/Chorion Composite Graft: Implications for Chronic Wound Healing. International Wound Journal, 10, 493-500. https://doi.org/10.1111/iwj.12140

[7] Koob, T.J., Lim, J.J., Zabek, N. and Massee, M. (2015) Cytokines in Single Layer Amnion Allografts Compared to Multilayered Amnion/Chorion Allografts for Wound Healing. Journal of Biomedical Materials Research Part B: Applied Biomaterials, 103, 1133-1140. https://doi.org/10.1002/jbm.b.33265

[8] Koob, T.J., Lim, J.J., Massee, M., Zabek, N. and Denoziere, G. (2014) Properties of Dehydrated Human Amnion/Chorion Composite Grafts: Implications for Wound Repair and Soft Tissue Regeneration. Journal of Biomedical Materials Research Part B: Applied Biomaterials, 102, 1353-1362. https://doi.org/10.1002/jbm.b.33141

[9] Koob, T.J., Lim, J.J., Massee, M., Zabek, N., Rennert, R., Gurtner, G., et al. (2014) Angiogenic Properties of Dehydrated Human Amnion/Chorion Allografts: Therapeutic Potential for Soft Tissue Repair and Regeneration. Vascular Cell, 6, Article No. 10. https://doi.org/10.1186/2045-824X-6-10

[10] Matthews, M.R., Quan, A.N., Weir, A.S., Foster, K.N. and Caruso, D.M. (2018) Temporary Abdominal Closure Combined with an Irrigating System Utilizing Hypochlorous Acid Solution to Decrease Abdominal Mucopurulence. ePlasty, 18, Article No. e12.

[11] Thornburg, D.A., Kowal-Vern, A., Tettelbach, W.H., Foster, K.N. and Matthews, M.R. (2021) Complex Limb Salvage with Placental-Based Allografts: A Pilot Study. Surgical Science, 12, 76-94. https://doi.org/10.4236/ss.2021.123010

[12] Glat, P.M. and Davenport, T. (2017) Using Dehydrated Human Amnion/Chorion Membrane Allografts as an Adjunctive Treatment along the Reconstructive Ladder. Annals of Plastic Surgery, 78, S14-S18. https://doi.org/10.1097/SAP.0000000000000980

[13] Lei, J., Priddy, L.B., Lim, J.J., Massee, M. and Koob, T.J. (2017) Identification of Extracellular Matrix Components and Biological Factors in Micronized Dehydrated Human Amnion/Chorion Membrane. Advances in Wound Care, 6, 43-53. https://doi.org/10.1089/wound.2016.0699

[14] Suzuki, K., Michael, G. and Tamire, Y. (2016) Viable Intact Cryopreserved Human Placental Membrane for a Non-Surgical Approach to Closure in Complex Wounds. Journal of Wound Care, 25, S25-S31. https://doi.org/10.12968/jowc.2016.25.Sup10.S25

[15] Ang, J., Chih-Kang, D.L. and Schneider, H.P. (2018) The Role of Placental Membrane Allografts in the Surgical Treatment of Tendinopathies. Clinics in Podiatric Medicine and Surgery, 35, 311-321. https://doi.org/10.1016/j.cpm.2018.02.004 